$6-2020$

Determinants of occupational hazards knowledge and safety practices among textile workers in Karachi, Pakistan: A cross sectional study

Natasha Shaukat

Hasan Nawaz Tahir

Tanzil Jamali

Mohammed Moizul Hassan

Asaad Ahmed Nafees

Follow this and additional works at: https://ecommons.aku.edu/pakistan_fhs_mc_chs_chs

Part of the Occupational Health and Industrial Hygiene Commons 


\title{
Determinants of occupational hazards knowledge and safety practices among textile workers in Karachi, Pakistan: a cross sectional study
}

\author{
Natasha Shaukat, ${ }^{1}$ Hasan Nawaz Tahir, ${ }^{2}$ Tanzil Jamali, ${ }^{3}$ Mohammed Moizul Hassan, ${ }^{4}$ Asaad Ahmed Nafees ${ }^{5}$
}

\begin{abstract}
Objective: To determine the factors associated with good knowledge and safe practices regarding occupational hazards among textile workers.

Methods: The cross-sectional study was conducted in Karachi from September 2015 to February 2016, and comprised male workers from seven textile mills. A 45-item structured questionnaire was developed and pretested in Urdu, the local language. One part of the questionnaire comprised 31 items related to good knowledge, and the other part comprised 14 items related to safe practices. Data was analysed using SPSS 19.

Results: Of the 300 subjects, 123(41\%) were aged 18-27 years, 183(63\%) were educated, 184(61.3\%) worked more than eight hours daily, 170(57\%) were employed in the weaving section and 164(55\%) as machine operators. Besides, 231(77\%) had good knowledge, and 62(21\%) reported safe practices. Educated workers were more likely $(p<0.05)$, and machine operators were less likely $(p<0.05)$ to have good knowledge, while educated workers, those in the spinning section and those working less than 8-hours daily $(p<0.05)$ were more likely to report safe practices. Conclusion: There was a high knowledge level, but a wide gap in adopting safety practices, which indicates need for focused interventions targeting high-risk workers and regulation of working hours.

Keywords: Textile industries, Health knowledge, Attitudes, Practice, Cotton fibre, Safety management, Occupational health, Pakistan. (JPMA 70: 958; 2020) DOI: https://doi.org/10.5455/JPMA.302642179
\end{abstract}

\section{Introduction}

Textile workers are occupationally exposed to several detrimental health hazards at their workplace that include accidents and injuries due to machinery or material handling, fall, cotton dust inhalation, noise emission, heat stress, fires, chemicals and dyeing hazards.1,2 Hazardous exposure to cotton dust leads to several respiratory symptoms and diseases among textile workers, including cough, wheezing, chest tightness, dyspnoea, byssinosis and chronic bronchitis.3,4

Occupational health and safety situation in the developed world has remarkably improved. ${ }^{5}$ On the contrary, the priorities in developing countries still remain different, with little or no measures taken towards workers' safety and health. ${ }^{5}$ A study from Thailand among garment workers found prevalence of respiratory symptoms to be $22.3 \%$, with past history of respiratory disease as a statistically significant predictor of respiratory symptoms (odds ration $[O R]=12.96$ ). This study also reported low knowledge levels regarding occupational lung disease, mean score of $7.59 \pm 0.89$ and low mean prevention

1,2,5 Department of Community Health Sciences, Aga Khan University, Karachi, ${ }^{3}$ Department of Community Health Sciences, Jinnah Medical and Dental College, Karachi, ${ }^{4}$ Aga Khan University, Karachi, Pakistan.

Correspondence: Asaad Ahmed Nafees. Email: asaad.nafees@aku.edu practices score of $8.82 \pm 3.43 .^{6}$ Another study from Nigeria among textile workers reported that most workers had good knowledge $(74 \%)$, and positive attitude $(81 \%)$, while only $20 \%$ had safe practices. Important predictors of workers' knowledge, and attitude identified by the Nigerian study were formal education, permanent employment and working $<5$ days a week. ${ }^{7}$

Cotton is amongst the leading crops in Pakistan, and the cotton textile industry accounts for $52 \%$ of total exports and $46 \%$ of all manufacturing, providing employment to almost $40 \%$ of the national labour force. ${ }^{8}$ Although a large workforce is associated with this sector, scarce data is available in Pakistan regarding their knowledge, attitude and practices (KAP) related to occupational exposures. A previous study in Pakistan showed that the textile workers had good knowledge (49\%) and appropriate attitude (81\%) and practices (20\%)..$^{9}$ Another study from Karachi reported $72 \%$ usage of safety gadgets (facemasks) in the spinning section of textile mills. ${ }^{10}$ However, there was a lack of robust scientific KAP assessment in the few previous studies from Pakistan, which did not use a structured or validated tool for assessment. 9

Recent studies conducted have largely focussed on assessing the prevalence of respiratory symptoms and diseases in textile workers.11-13 KAP surveys among workers regarding hazards are important for generating 
insights about their belief, preconceived notions, attitudes and ongoing practices. They are commonly used for designing effective health promotion strategies and programmes. The current study was planned to determine the factors associated with good knowledge, appropriate attitude and safe practices regarding occupational hazards among textile workers in Karachi.

\section{Subjects and Methods}

The cross-sectional study was conducted from September 2015 to February 2016 at textile mills in Karachi. The study was part of the larger 'Multifaceted intervention package for respiratory health of textile workers' (MultiTex) study. ${ }^{14}$ It aims at determining the effectiveness of a multifaceted intervention package for improvement in KAP as well as respiratory health of textile workers in Karachi, which is a metropolis located in the southern region of Pakistan, and the capital of Sindh province, and is a commercial hub and accounts for up to $50 \%$ of national economic output, hosting a large number of industries. ${ }^{15}$ According to the Labour Force Survey 2015, approximately 14.31 million people work in Sindh, ${ }^{16}$ while the exact workforce in Karachi is unknown. As much as about $50 \%$ of Pakistan's employment is thought to be in the cottage industries or informal sector in urban areas, with $23 \%$ engaged in Sindh. ${ }^{17}$ Karachi is the centre of textile industry in Pakistan, where an estimated 4500 industrial units operate in the formal sector. ${ }^{12}$

The current study was conducted at seven textile mills that were selected purposefully from different industrial areas, including Korangi and Sindh Industrial Trading Estate (SITE). These industries varied from small to large mills comprising a workforce ranging from 500 to 4000 workers, while production sections primarily included weaving, spinning, dyeing and stitching.

After approval from the ethics review committee of Aga Khan University, Karachi, male textile workers aged 18 years and above who were present on the day of data collection and who consented to participate were included. Those absent from work on the day of the visit, administrative staff and those who refused to participate were excluded. Interviews with the subjects were conducted in a separate quiet room identified within the textile mill through the assistance of the administrative staff.

Post hoc sample size was calculated using World Health Organisation (WHO) sample size calculator while assuming the prevalence of knowledge to be $48.9 \%$, and practices $20 \% .^{1}$ A sample size of 385 was required to achieve a $95 \%$ confidence level and $5 \%$ bound on error for an estimated prevalence of knowledge at $48.9 \% .^{9}$
Data collection was done through face-to-face interviews by trained data collectors. A structured questionnaire was specifically developed for assessing occupational hazards and safety-related knowledge and safety practices of textile workers with the help of literature search. ${ }^{18}$ The questionnaire had sections on socio-demographic, workrelated information, knowledge and safety practices on occupational exposures. The knowledge section focused on hazards in the textile industry, with questions related to cotton dust exposure and its health outcome. The questions on cotton dust were on particle size, permissible limits, section of industry with maximum exposure, job designation, and symptoms of health effects from cotton dust, health and safety instructions and use of personal protective equipment (PPE).

The safety practices section focused on these key areas, but they were on the routine practices of workers in the mills, which included the use of PPE. Some questions regarding mopping practices and ventilation issues related to the organisation/mill's practices were also included.

Focus group discussions (FGDs) with textile mill workers of a non-participating mill were also conducted, which were helpful in further refining the tool. Face validity of the tool was assessed through expert review and the questionnaire was translated into local language Urdu, followed by backtranslation into English. It was pretested in the field before a final version in Urdu was prepared. The questionnaire contained a total of 45 items; 31 assessing knowledge, and 14 assessing practices of textile workers.

Data were entered in Epi data 3.1, and analysed using SPSS 19. Open-ended questions were categorised and responses to knowledge and practices items were coded into binary outcome variables (yes/no). Mean scores were calculated for these variables by adding all questions responded correctly out of the total, followed by calculating mean percentage scores. Participants who scored $>50 \%$ were categorised as having good knowledge and safety practices. ${ }^{7}$

To assess the relation between variables and underlying factors, cross-tabs, univariate and multivariate logistic regression analyses were performed. Multi-collinearity was assessed using Crammers V/Phi (cut-off value $\geq 0.5$ ) in univariate model for knowledge, and was found to be high between days per week and hours per day, therefore days per week was not carried forward for multivariate model for knowledge assessment. Good knowledge and safety practices were taken as dependent variables and socio-demographic and work-related variables were taken as independent variables. Univariate OR and their 
$95 \%$ confidence intervals (Cls) were reported. All variables having $\mathrm{p} \leq 0.25$ were assessed further in multivariable regression models.

\section{Results}

Of the 300 subjects,123(41\%) were aged 18-27 years, $183(61 \%)$ were educated, 175(58\%) had worked for a duration of less than 10 years, 184(63.3\%) were working more than eight hours daily, 170(57\%) were employed in the weaving section and $164(55 \%)$ as machine operators (Table-1).

Table-1: Distribution of socio-demographic and occupational factors among textile workers, Karachi, Pakistan, $2016(\mathrm{n}=300)$.

\begin{tabular}{|c|c|c|}
\hline Variables & Frequency (n) & Percentage (\%) \\
\hline \multicolumn{3}{|c|}{ Age of participants in years } \\
\hline $18-27$ & 123 & 41 \\
\hline $28-37$ & 116 & 38.7 \\
\hline$\geq 38$ & 61 & 20.3 \\
\hline \multicolumn{3}{|l|}{ Ethnicity } \\
\hline Punjabi & 109 & 36.3 \\
\hline Sindhi & 36 & 12 \\
\hline 0thers* & 55 & 51.7 \\
\hline \multicolumn{3}{|l|}{ Educational status\# } \\
\hline Uneducated & 111 & 37 \\
\hline Educated & 189 & 63 \\
\hline \multicolumn{3}{|c|}{ Duration of work in years } \\
\hline$<10$ & 175 & 58.3 \\
\hline$>10$ & 125 & 41.7 \\
\hline \multicolumn{3}{|c|}{ Working hours per day } \\
\hline$\leq 8$ & 116 & 38.7 \\
\hline$>8$ & 184 & 61.3 \\
\hline \multicolumn{3}{|l|}{ Days per week } \\
\hline$\leq 6$ & 228 & 76 \\
\hline$>6$ & 72 & 24 \\
\hline \multicolumn{3}{|l|}{ Job designation } \\
\hline Administrative staff & 32 & 10.7 \\
\hline Helper & 59 & 19.7 \\
\hline Jobber & 20 & 6.7 \\
\hline Operator & 164 & 54.7 \\
\hline Master & 25 & 8.3 \\
\hline \multicolumn{3}{|l|}{ Section of mill } \\
\hline Administrative unit\$ & 37 & 12.3 \\
\hline Spinning & 32 & 10.7 \\
\hline Weaving & 170 & 56.7 \\
\hline Stitching & 61 & 20.3 \\
\hline \multicolumn{3}{|l|}{ Working shiftst } \\
\hline Fixed & 213 & 71 \\
\hline Alternating & 87 & 29 \\
\hline \multicolumn{3}{|l|}{ Employment status } \\
\hline Permanent & 150 & 50 \\
\hline Contract & 150 & 50 \\
\hline
\end{tabular}

*other languages : Baluchi, Urdu and Pushto

\# uneducated : lack of formal education

$\$$ administrative unit: staff involved in maintenance, electrical and air conditioning related work † fixed: morning shift only; alternating: 15 days' rotations in morning, evening and night shifts
Table-2: Multivariate logistic regression analysis for factors associated with good knowledge among textile workers, Karachi, Pakistan, 2016 ( $\mathrm{n}=300)$.

\begin{tabular}{lccc}
\hline Variables & Crude Odds & p-value & Adjusted Odds \\
Ratio & p-value \\
& $(95 \% \mathrm{Cl})$ & $(95 \% \mathrm{Cl})$ \\
\hline
\end{tabular}

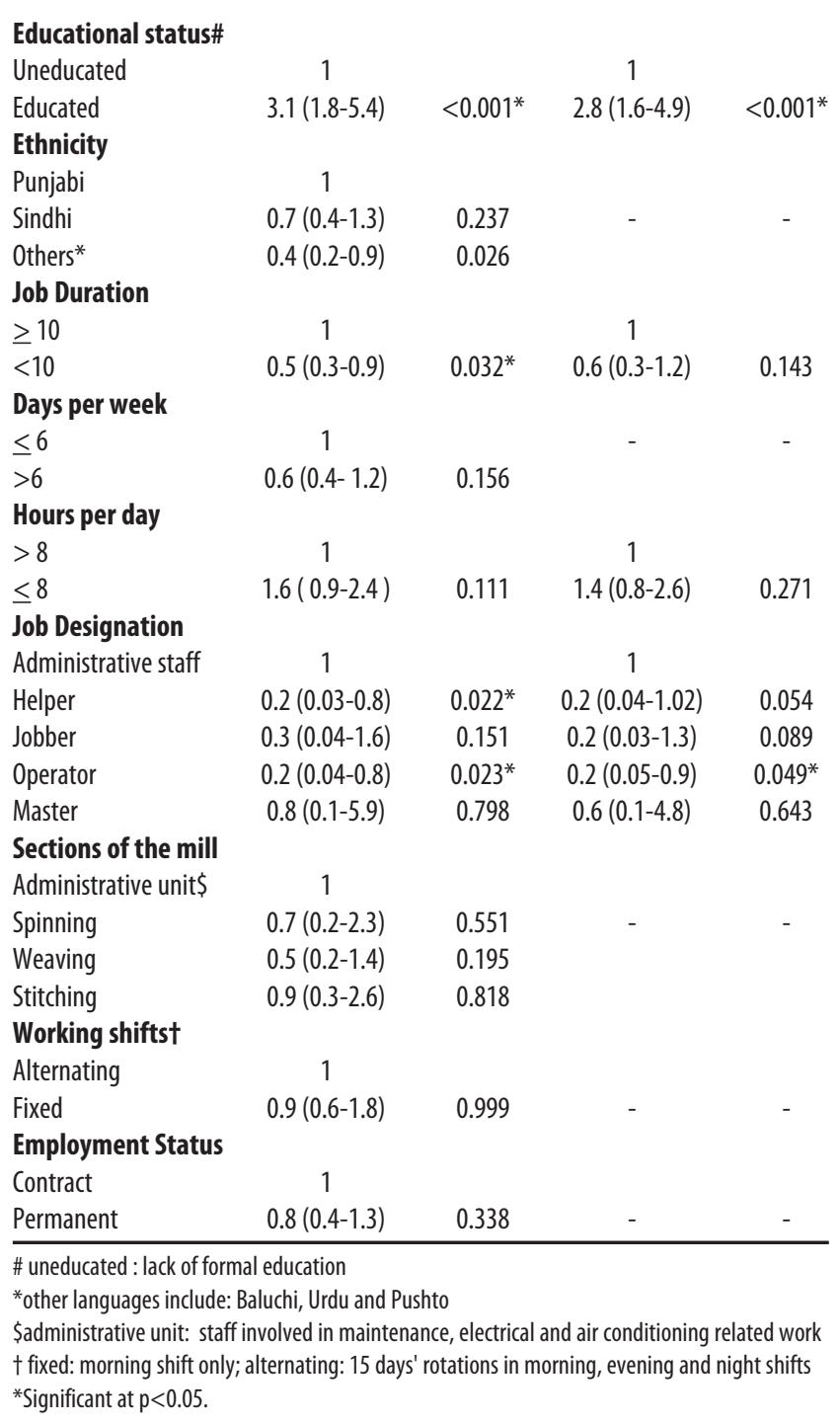

Besides, 231(77\%) had good knowledge, 280(93\%) had appropriate attitude, and $62(21 \%)$ reported safe practices.

In univariate logistic regression analysis, educational status, job designation, section of the mill, job duration, hours per week, days per week and ethnicity were found to be associated with good knowledge and safe practices, but multivariate logistic regression analysis showed that educated workers were more likely and machine operators were less likely to have good 
Table-3: Multivariate logistic regression analysis for factors associated with safe practices among textile workers Karachi, Pakistan, $2016(n=300)$.

\begin{tabular}{|c|c|c|c|c|}
\hline Variables & $\begin{array}{c}\text { Crude Odds } \\
\text { Ratio } \\
(95 \% \mathrm{Cl})\end{array}$ & p-value & $\begin{array}{c}\text { Adjusted Odds } \\
\text { Ratio } \\
(95 \% \mathrm{Cl})\end{array}$ & $\overline{p \text {-value }}$ \\
\hline
\end{tabular}

\begin{tabular}{|c|c|c|c|c|}
\hline \multicolumn{5}{|l|}{ Educational status\# } \\
\hline Uneducated & 1 & & 1 & \\
\hline Educated & $2.6(1.3-5.1)$ & $0.004^{*}$ & $2.4(1.2-4.8)$ & $0.016^{*}$ \\
\hline \multicolumn{5}{|l|}{ Ethnicity } \\
\hline Punjabi & 1 & & & \\
\hline Sindhi & $0.9(0.4-2.5)$ & 0.923 & - & - \\
\hline 0thers* & $1.1(0.6-1.9)$ & 0.827 & & \\
\hline \multicolumn{5}{|l|}{ Job Duration } \\
\hline$\geq 10$ & 1 & & & \\
\hline$<10$ & $1.2(0.6-2.1)$ & 0.596 & - & - \\
\hline \multicolumn{5}{|l|}{ Days per week } \\
\hline$\leq 6$ & 1 & & 1 & \\
\hline$>6$ & $0.5(0.2-1.0)$ & 0.054 & $1.26(0.5-2.9)$ & 0.585 \\
\hline \multicolumn{5}{|l|}{ Hours per day } \\
\hline$>8$ & 1 & & 1 & \\
\hline$\leq 8$ & $3.5(1.9-6.3)$ & $<0.001^{*}$ & $2.3(1.2-4.5)$ & $0.013^{*}$ \\
\hline \multicolumn{5}{|l|}{ Job Designation } \\
\hline Administrative staff & 1 & & & \\
\hline Helper & $0.9(0.3-2.3)$ & 0.781 & - & - \\
\hline Jobber & $0.9(0.2-3.0)$ & 0.805 & & \\
\hline Operator & $0.5(0.2-1.1)$ & 0.102 & & \\
\hline Master & $0.9(0.3-3.2)$ & 0.994 & & \\
\hline \multicolumn{5}{|l|}{ Sections of the mill } \\
\hline Administrative unit\$ & 1 & & 1 & \\
\hline Spinning & $4.0(1.4-11.2)$ & 0.008 & $3.2(1.1-9.4)$ & $0.031^{*}$ \\
\hline Weaving & $0.6(0.3-1.5)$ & 0.304 & $0.9(0.4-2.3)$ & 0.879 \\
\hline Stitching & $0.4(0.1-1.04)$ & 0.061 & $0.4(0.1-1.3)$ & 0.143 \\
\hline \multicolumn{5}{|l|}{ Working shiftst } \\
\hline Alternating & 1 & & & \\
\hline Fixed & $0.90(0.5-1.7)$ & 0.749 & - & - \\
\hline \multicolumn{5}{|l|}{ Employment Status } \\
\hline Contract & 1 & & & \\
\hline Permanent & $0.8(0.5-1.5)$ & 0.569 & - & - \\
\hline
\end{tabular}

\# uneducated means lack of formal education

*other languages include: Baluchi, Urdu and Pushto

\$includes staff involved in maintenance, electrical and air conditioning related work

tfixed: morning shift only; alternating: 15 days' rotations in morning, evening and night shifts

*Significant at $\mathrm{p}<0.05$.

knowledge (Table-2). Educated workers, those working in the spinning section, and those working for less than 8hours daily were more likely to report safe practices at work (Table-3).

\section{Discussion}

The study adds to the existing body of literature regarding textile workers' KAP regarding occupational hazards, using a specifically-developed, structured and comprehensive questionnaire. We found high prevalence of good knowledge (77\%), appropriate attitude (93\%) and low prevalence of safe practices (21\%). The study identified independent predictors, like educational status, working hours and section of the mill, for good knowledge and safe practices.

The prevalence of good knowledge among textile workers was $77 \%$ which is high in comparison to studies conducted in Nigeria, Ethiopia and previously in Pakistan (3.7-69\%).5,9,19,20 However, it is comparable to a study from southern Ethiopia. ${ }^{3}$ These differences may be due to various methodological differences, including; sampling technique, study tool and data collection procedures. Working environment, occupational health and safety policies and regulations, availability and accessibility of PPE also varies from country to country.

However, in our study this high level of good knowledge did not result into safe practices as the prevalence of safe practices was $20 \%$ which is the lowest compared to other developing countries (54-82\%).3,5,21,22 This finding is comparable to a previous study in Pakistan. ${ }^{9}$ This alarmingly low rate of safe practices means that the workers in Pakistan are at high risk of health hazards which calls for provision of conducive environment at workplace, ensuring regular provision and facilitating the use of PPE.

The current study found higher odds of safe practices amongst educated workers, compared to the uneducated, which is similar to previous studies conducted in Nigeria and Pakistan.9,23 It seems that with education comes awareness that enables workers to make choices for their own safety and occupational health.

In the current study, working $<8$ hours per day was found to be a strong independent predictor of safe practices. Those working fewer number of hours were more likely to have safer practices compared to those who were not. This is comparable to a study conducted in southern Ethiopia ${ }^{3}$ which also demonstrated that it is more feasible to utilise PPE for shorter durations. This implies that administrative measures are needed in adjusting work schedules of workers in order to encourage and increase the usage of PPE. Working hours may also be related to experience; more experienced workers may be working comparatively fewer hours compared to the inexperienced ones.

Another significant finding of this study was that workers in the spinning section had higher odds of safe practices compared to those working in other sections. This finding is similar to a previous study in Pakistan where workers in 
the weaving section were found less likely to have appropriate practices. ${ }^{9}$ This may be due to heavier work requirements and environmental factors which cause hindrance in the uptake and use of PPE. Attention needs to be directed towards these sections in order to make the workplace more conducive to the needs of occupational health of the workers.

We believe that this study is unique in terms of using a comprehensive, structured questionnaire, developed specifically for textile workers, which extensively assessed their knowledge and practices. Moreover, various quality assurance mechanisms were in place: trainings were provided for uniformity in data collection supplemented with regular supervisory visits.

However, the study has its limitations. We could only recruit male textile workers, as the selected sections comprised primarily male workers. Due to logistical issues, we could only recruit mills from urban areas in Karachi city, while health and safety culture and conditions may be worse in mills in rural districts. However, since Karachi hosts a large number of industries, we believe that we were able to capture a diverse group of textile workers belonging not only to Karachi but also to rural districts of different provinces. Another important limitation could be a healthy worker bias, implying that the available workers would tend to have better knowledge and attitudes thus leading to overestimation of the results, but we may have not been able to adjust for this limitation. Social desirability bias may also have limited some of the responses in the sense that the participants may have reported socially acceptable answers rather than their actual practices; though this would have been reduced to an extent since extensive training was provided to our field staff. Another limitation could be the fact that the study questionnaire focussed primarily on cotton dust exposure when the workers are exposed to several other important hazards which we could not be captured in sufficient detail.

\section{Conclusion}

Important gaps in knowledge and practices were identified which call for attention towards the provision of occupational health and safety trainings towards increasing PPE usage. There is a need to ensure conducive work environment and workplace regulations focussing on high-risk workers and reducing working hours.

Disclaimer: Findings of the study were presented at the European Respiratory Society International Congress held in Milan, Italy, in September 2017, and at the World Congress on Occupational Health and Safety held in Singapore, in September 2017.
Conflict of Interest: None.

Source of Funding: The Higher Education Commission (HEC), Pakistan (Grant No 20-2759/ R\&D/HEC/12).

\section{References}

1. Sudha B, Meenaxi T. Occupational health hazards in textiles industry. Asian J Home Sci. 2014; 9:267-71.

2. Rongo L, De Haan S, Barten F, Msamanga G, Dolmans W, Van Naerssen $T$, et al. Felt Occupational and Environmental Health hazards among Workers in small-scale industries in Dar es Salaam, Tanzania: Focus group discussion study. East Afr J Public Health. 2005; 2:21-6.

3. Tadesse S, Kelaye T, Assefa Y. Utilization of personal protective equipment and associated factors among textile factory workers at Hawassa Town, Southern Ethiopia. J Occup Med Toxicol 2016;11:e6. doi: 10.1186/s12995-016-0096-7.

4. Lai PS, Christiani DC. Long term respiratory health effects in textile workers. Curr Opin Pulm Med. 2013; 19:152-7.

5. Tetemke D, Alemu K, Tefera Y, Sharma H, Worku W. Knowledge and practices regarding safety information among textile workers in Adwa town, Ethiopia. J Health Sci. 2014; 1:e00015.

6. Chumchai P, Silapasuwan P, Wiwatwongkasem C, Arphorn S, Suwan-ampai P. Prevalence and Risk Factors of Respiratory Symptoms Among Home-Based Garment Workers in Bangkok, Thailand. Asia Pac J Public. 2015; 27:461-8.

7. Okafoagu NC, Oche M, Awosan KJ, Abdulmulmuni HB, Gana GJ, Ango JT, et al. Determinants of knowledge and safety practices of occupational hazards of textile dye workers in Sokoto, Nigeria: a descriptive analytic study. J Public Health Afr 2017;8:e664. doi: 10.4081/jphia.2017.664.

8. Textile Industry's economic contribution 2011-12. Pakistan Economic Survey. State Bank of Pakistan. [Online] [Cited 2017 Feb 17]. Available from: URL: https://aptma.org.pk/pak_textile_statistics/tec.php.

9. Khoso A, Nafees AA. Knowledge, attitude and practices regarding respiratory symptoms among textile workers of Karachi, Pakistan: a cross-sectional survey. J Pak Med Assoc. 2015; 65:17-23.

10. Farooque MI, Khan B, Aziz E, Moosa M, Raheel M, Kumar S, et al. Byssinosis: as seen in cotton spinning mill workers of Karachi. J Pak Med Assoc. 2008; 58:95-8.

11. Nafees AA, Fatmi Z, Kadir MM, Sathiakumar N. Pattern and predictors for respiratory illnesses and symptoms and lung function among textile workers in Karachi, Pakistan. Occup Environ Med. 2013; 70:99-107.

12. Nafees AA, Fatmi Z, Kadir MM, Sathiakumar N. Chronic bronchitis and chronic obstructive pulmonary disease (COPD) among Textile workers in Karachi, Pakistan. J Coll Physicians Surg Pak. 2016; 26:384-9.

13. Memon I, Panhwar A, Rohra DK, Azam Sl, Khan N. Prevalence of byssinosis in spinning and textile workers of Karachi, Pakistan. Arch Environ Occup Health. 2008; 63:137-42.

14. Ali NA, Nafees AA, Fatmi Z, Azam SI. Dose-response of cotton dust exposure with lung function among textile workers: MultiTex study in Karachi, Pakistan. Int J Occup Environ Med. 2018; 9:120-8.

15. Government of Pakistan. Ministry of Finance, Pakistan. Pakistan economic survey. Population, Labour Force and Employment. [Online] 2015 [Cited 2017 February 20]. Available from: URL:http://www.finance.gov.pk/survey/chapters_15/12_Populati on.pdf.

16. Pakistan Bureau of Statistics. Labour Force Survey. Islamabad .[Online] 2015.[Cited 2018 February 10]. Available from: URL:http://www.pbs.gov.pk/content/labour-force-survey-201415-annual-report.

17. Pakistan Bureau of Statistics.Labour Force Statistics. [Online] [Cited 20182 15].Availablefrom: URL:http://www.pbs.gov.pk/ 
sites/default/files//Labour\%20Force/publications/lfs2013-14/t27pak-fin.pdf.

18. Geer LA, Curbow BA, Anna DH, Lees PS, Buckley TJ. Development of a questionnaire to assess worker knowledge, attitudes and perceptions underlying dermal exposure. Scand JEnviron Health. 2006; 32:209-16.

19. Akintayo W. Knowledge, attitude and practice on the use of personal protective equipment by traditional resist Fabrics workers in Abeokuta, Nigeria. Arabian J Bus Manag Review. 2013; 2:27.

20. Truong CD, Siriwong W, Robson MG. Assessment of knowledge, attitude and practice on using of personal protective equipment in rattan craftsmen at trade village, Kienxuong district, Thaibinh province, Vietnam. Warasan Wichai Witthayasat Kanphaet. 2009; 23: 1-4.

21. Aluko OO, Adebayo AE, Adebisi TF, Ewegbemi MK, Abidoye AT, Popoola BF. Knowledge, attitude, and practice of dyeing and printing workers. Indian J Community Med. 2010;35(4):498.

22. Aluko OO, Adebayo AE, Adebisi TF, Ewegbemi MK, Abidoye AT, Popoola BF. Occupational exposure and health problems in smallscale industry workers in Dar es Salaam, Tanzania: a situation analysis. BMC Res Notes. 2016; 9:71.

23. Aluko OO, Adebayo AE, Adebisi TF, Ewegbemi MK, Abidoye AT, Popoola BF. Knowledge, attitudes and perceptions of occupational hazards and safety practices in Nigerian healthcare workers. BMC Res Notes. 2016; 9:71. 